\title{
Treatment of heart failure in the elderly in Poland. The results of the Polish part of EURObservational Research Programme: The Heart Failure Pilot Survey
}

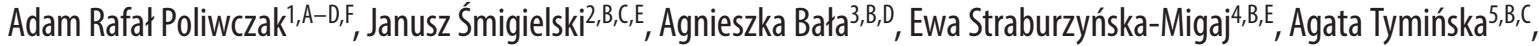

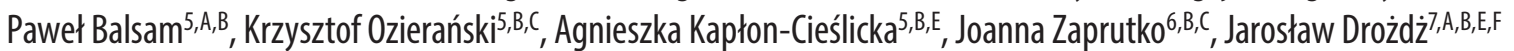 \\ ${ }^{1}$ Department of Human Physiology, Medical University of Lodz, Poland \\ 2 State Higher Vocational School of Konin, Poland \\ ${ }^{3}$ Department of Internal Diseases and Clinical Pharmacology, Medical University of Lodz, Poland \\ ${ }^{4}$ jt $^{\text {st }}$ Department of Cardiology, Poznan University of Medical Sciences, Poland \\ ${ }^{5} 1^{\text {st }}$ Chair and Department of Cardiology, Medical University of Warsaw, Poland \\ ${ }^{6} 2^{\text {nd }}$ Department of Cardiology, Poznan University of Medical Sciences, Poland \\ ${ }^{7}$ Department of Cardiology, Medical University of Lodz, Poland \\ A - research concept and design; $\mathrm{B}$ - collection and/or assembly of data; $\mathrm{C}$ - data analysis and interpretation; \\ $D$ - writing the article; $E$ - critical revision of the article; $F$ - final approval of the article
}

Address for correspondence

Adam Poliwczak

E-mail: polczak@mp.pl

Funding sources

None declared

Conflict of interest

None declared

Received on August 13, 2018

Reviewed on December 9,2018

Accepted on February 18, 2019

Published online on May 6, 2019

Cite as

Poliwczak R, Śmigielski J, Bała A, et al. Treatment of heart failure in the elderly in Poland. The results of the Polish part of EURObservational Research Programme: The Heart Failure Pilot Survey. Adv Clin Exp Med. 2019;28(10):1351-1358. doi:10.17219/acem/104527

DOI

10.17219/acem/104527

Copyright

Copyright by Author(s)

This is an article distributed under the terms of the

Creative Commons Attribution Non-Commercial License

(http://creativecommons.org/licenses/by-nc-nd/4.0/)

\section{Abstract}

Background. Pharmacotherapy remains the fundamental method of treating heart failure (HF). Treatment of the elderly is less based on the principles of evidence-based medicine (EBM) and doses do not reach the prescribed value.

Objectives. The aim of the study was to identify any distinct treatment of HF in the elderly compared to those under 65 years of age.

Material and methods. This study describes the Polish part of the EURObservational Research Programme: The Heart Failure Pilot Survey (ESC-HF Pilot). Eligibility to the program was limited to people with HF in 26 centers in Poland. After the first phase, more data was collected at 3 and 12 months. It covered a total of 893 people.

Results. Treatment of HF is conducted largely in accordance with the applicable guidelines. The percentage of people over 65 years of age who use angiotensin-converting-enzyme inhibitors/angiotensin- $\|$ receptor blockers (ACE-I/ARB), B-blockers and mineralocorticoid-antagonists remains high. Also, during the 12-month follow-up the frequency of the use of $\beta$-blockers did not decrease, and a decrease in the number subjects treated with ACE-I was compensated by increasing percentage of the use of ARB. A major problem also seems to be the appropriate treatment to prevent thromboembolic complications in the case of coexistence of atrial fibrillation (AF). There is a large group of older people who do not receive proper anticoagulation.

Conclusions. The study showed the existence of differences in the treatment of HF in the elderly. It partly does not proceed in accordance with the guidelines, especially in the presence of multiple comorbidities.

Key words: pharmacotherapy, elderly, heart failure treatment 


\section{Introduction}

Despite significant progress, the length and quality of life of patients with heart failure (HF) remains insufficient. Heart failure is a major cause of hospitalization and disability in the elderly. ${ }^{1-4}$ In these patients, the prognosis deteriorates due to the coexistence of many other diseases. Making a proper diagnosis of HF based on the definition contained in the ESC guidelines may be problematic. Common symptoms such as shortness of breath, decreased exercise tolerance and peripheral edema may result from a variety of diseases. ${ }^{2-6}$ In clinical trials on HF treatment, older people, i.e., above 65 years, are underrepresented. ${ }^{7-10}$ Only a few of clinical trials have been dedicated to the elderly. ${ }^{11}$ In previous studies, we found that treatment of the elderly is less based on the principles of EBM, and drug doses do not reach the prescribed value. ${ }^{12-14}$ Older people are more exposed to side effects and more at risk of possible interactions. This is related to changes in drug metabolism, impairment of kidney and liver function, and increased polypragmasy. ${ }^{15}$ Age is also an unfavorable prognostic factor in HF. ${ }^{16}$ According to the current standards, HF pharmacotherapy is based on ACE inhibitors/AT1 receptor-blockers, selected beta-blockers, mineralocorticoid receptor blockers, and ivabradine. It has been shown that these drug groups have a positive effect on prolonging survival. In addition, symptomatic and quality-of-life medicines are used, such as diuretics, digoxin and nitrates. ${ }^{3}$

\section{Methods}

This study describes the Polish part of the trial - EURObservational Research Programme: The Heart Failure Pilot Survey (ESC-HF Pilot). Its methodology has been described in previous publications. ${ }^{17}$ The study involved 136 cardiac centers in 12 European countries. In Poland, the study was conducted in 26 centers. Patients were enrolled between October 2009 and May 2010 and divided into 2 groups. The first group comprised patients who had previously been diagnosed with chronic HF and qualified during the next visit to the cardiology outpatient clinic. The second group consisted of patients admitted to hospital with acute HF, requiring administration of intravenous therapy with positive inotropic drugs, vasodilators and diuretics. There were no specific exclusion criteria of the study, except for age. All qualified patients had to be at least 18 years old. All participants expressed voluntary consent in accordance with the Declaration of Helsinki (1975) and the consent of the Commission of Bioethics, Medical University of Lodz (RNN/214/09/EC) was obtained. After the first phase, more data on the treatment and the fate of the participants was collected after 12 months.

The aim of this work was to analyze the treatment of HF and the use of additional treatment in the group of people
65 years of age and older in comparison with the rest of the population. We tried to find possible differences in the treatment of both groups.

\section{Statistical methods}

The data was verified for normality of distribution and equality of variances. The normality of the distribution was checked using the Shapiro-Wilk test. Comparison of gender, smoking status, place of treatment, HF etiology, presence of kidney disease, and other comorbidities, as well as population structure analysis was performed by using $X^{2}$ test. The Student's t-test was used to compare the average age of participants. The statistical analysis was performed using STATISTICA v. 10 (StatSoft, Tulsa, USA). The results of the quantitative variables are presented as a mean \pm standard deviation (SD). Other results are presented as a percentage. The limit of statistical significance was set at $\mathrm{p}<0.05$.

\section{Results}

The study included a total of 893 people, including 650 (73\%) hospitalized patients and 243 (27\%) outpatients. The average age was 66.1 years $( \pm 13.2$ years). The basic information is summarized in Table 1 . Women accounted for a total of $34 \%$ and men of $66 \%$ of all patients studied. Among outpatients, women accounted for $28 \%$, men $72 \%$. In the case of hospital patients, these proportions were $36 \%$ and $65 \%$, respectively. Older people were characterized by a more severe HF assessed with the New York Heart Association Functional Classification (NYHA). Similarly, in the elderly, diabetes and atrial fibrillation (AF) were more common. Among patients with permanent AF, this was particularly evident in NYHA class II, where 19.15\% of younger and $34.23 \%$ of the older patients were treated for this reason. There were no statistically significant differences in drug doses between patients with AF and sinus rhythm in individual age groups (Table 4).

Pharmacological treatment of patients at the time of inclusion in the study showed a statistically significant difference in the frequency of use of different groups of drugs. The study looked at the treatment that took place before the patient was enrolled into the study, during the initial observation and after 12 months.

In the case of ACE-I, any preparation from this group of drugs was taken by $69 \%$ younger patients and only $58 \%$ of people aged 65 ( $\mathrm{p}<0.001)$. Also, during the initial observation, this difference remained ( $82 \%$ vs $73 \%, \mathrm{p}<0.005)$. After 12 months of follow-up, $80 \%$ of younger patients and $68 \%$ of older patients were still taking ACE-I. The frequency of ARB adoption did not differ significantly, both before inclusion and during the study: it was $8 \%$ compared to $12 \%(\mathrm{p}=0.760)$ before inclusion and $11 \%$ compared to $12 \%(\mathrm{p}=0.561)$ at baseline for younger vs older patients. 
Table 1. Basic characteristic of the studied population. It includes the percentage of women, etiologies of heart failure and the NYHA class, the place of treatment, the presence and basic treatment of diabetes and the presence and type of atrial fibrillation

\begin{tabular}{|c|c|c|c|}
\hline Parameters & $\begin{array}{c}<65 \text { years } \\
n=386\end{array}$ & $\begin{array}{c}\geq 65 \text { years } \\
n=507\end{array}$ & $\mathrm{p}$-value \\
\hline Women & 77 (20\%) & 223 (44\%) & $<0.001$ \\
\hline $\begin{array}{l}\text { CHF etiology: } \\
\text { ischemic } \\
\text { non-ischemic }\end{array}$ & $\begin{array}{l}182(47 \%) \\
204(53 \%)\end{array}$ & $\begin{array}{l}324(64 \%) \\
183(36 \%)\end{array}$ & $\begin{array}{l}<0.001 \\
<0.001\end{array}$ \\
\hline $\begin{array}{l}\text { NYHA class: } \\
\text { I } \\
\text { II } \\
\text { III } \\
\text { IV }\end{array}$ & $\begin{array}{c}26(7 \%) \\
156(41 \%) \\
129(34 \%) \\
72(19 \%)\end{array}$ & $\begin{array}{c}14(3 \%) \\
135(27 \%) \\
260(51 \%) \\
97(19 \%)\end{array}$ & $\begin{array}{c}<0.001 \\
<0.001 \\
<0.001 \\
\text { ns }\end{array}$ \\
\hline $\begin{array}{l}\text { Place of treatment: } \\
\text { hospital } \\
\text { outpatients }\end{array}$ & $\begin{array}{l}250(65 \%) \\
136(35 \%)\end{array}$ & $\begin{array}{c}400(79 \%) \\
107(21 \%)\end{array}$ & $\begin{array}{l}<0.001 \\
<0.001\end{array}$ \\
\hline $\begin{array}{l}\text { Chronic kidney } \\
\text { disease }\end{array}$ & $42(11 \%)$ & $130(26 \%)$ & $<0.001$ \\
\hline $\begin{array}{l}\text { Smoking status: } \\
\text { never } \\
\text { current } \\
\text { former }\end{array}$ & $\begin{array}{c}n=380 \\
106(28 \%) \\
76(20 \%) \\
198(52 \%)\end{array}$ & $\begin{array}{c}n=487 \\
248(51 \%) \\
30(6 \%) \\
209(43 \%)\end{array}$ & $\begin{array}{l}<0.001 \\
<0.001 \\
<0.001\end{array}$ \\
\hline $\begin{array}{l}\text { Diabetes } \\
\text { total } \\
\text { oral and diet } \\
\text { insulin } \\
\text { newly diagnosed }\end{array}$ & $\begin{array}{c}103(27 \%) \\
57(15 \%) \\
38(10 \%) \\
8(2 \%)\end{array}$ & $\begin{array}{c}195(38 \%) \\
107(21 \%) \\
79(16 \%) \\
9(2 \%)\end{array}$ & $\begin{array}{c}0.004 \\
0.003 \\
0.004 \\
\text { ns }\end{array}$ \\
\hline $\begin{array}{l}\text { Atrial fibrillation } \\
\text { total } \\
\text { paroxysmal } \\
\text { persistent } \\
\text { permanent }\end{array}$ & $\begin{array}{c}n=383 \\
120(31 \%) \\
25(7 \%) \\
20(5 \%) \\
75(20 \%)\end{array}$ & $\begin{array}{c}n=507 \\
241(48 \%) \\
75(15 \%) \\
29(6 \%) \\
137(27 \%)\end{array}$ & $\begin{array}{c}<0.001 \\
0.004 \\
\text { ns } \\
0.005\end{array}$ \\
\hline \multicolumn{4}{|c|}{ Permanent atrial fibrillation vs sinus rhythm amount NYHA class n (\%) } \\
\hline I & $\begin{array}{c}0(0 \%) / \\
23(100 \%)\end{array}$ & $\begin{array}{l}2(20 \%) / \\
8(80 \%)\end{array}$ & ns \\
\hline ॥ & $\begin{array}{l}27(19.15 \%) / \\
114(80.85 \%)\end{array}$ & $\begin{array}{l}38(34.23 \%) / \\
73(65.77 \%)\end{array}$ & 0.006 \\
\hline III & $\begin{array}{l}31(30.10 \%) / \\
72(69.90 \%)\end{array}$ & $\begin{array}{l}67(32.84 \%) / \\
137(67.16 \%)\end{array}$ & ns \\
\hline IV & $\begin{array}{l}17(25 \%) / \\
51(75 \%)\end{array}$ & $\begin{array}{c}30(38.96 \%) / \\
47(61.04 \%)\end{array}$ & ns \\
\hline
\end{tabular}

After 12 months $16 \%$ of younger patients vs $21 \%$ of older ones $(\mathrm{p}=0.043)$ continued to receive these drugs. Considering the frequency of using both classes of drugs together (ACE-I or ARB), before enrollment in the study, it was only $77 \%$ in the younger group and $69 \%$ in patients aged 65 years and older $(\mathrm{p}<0.001)$. At baseline observation, it increased to $93 \%$ and $86 \%$, respectively $(\mathrm{p}=0.006)$. After 12 months, it was $96 \%$ and $89 \%(\mathrm{p}=0.006)$, respectively.

Another basic class of drugs for the treatment of HF was $\beta$-blockers. Before inclusion, frequency of $\beta$-blocker therapy was $77 \%$ in the group of younger and $69 \%$ in the group of older patients and they statistically differed significantly ( $p=0.007)$. At baseline observation, the percentage of $\beta$-blocker therapy was $92 \%$ in younger patients and $89 \%$ in older ones, respectively, in both age groups. It did not differ statistically significantly $(\mathrm{p}=0.083)$. After

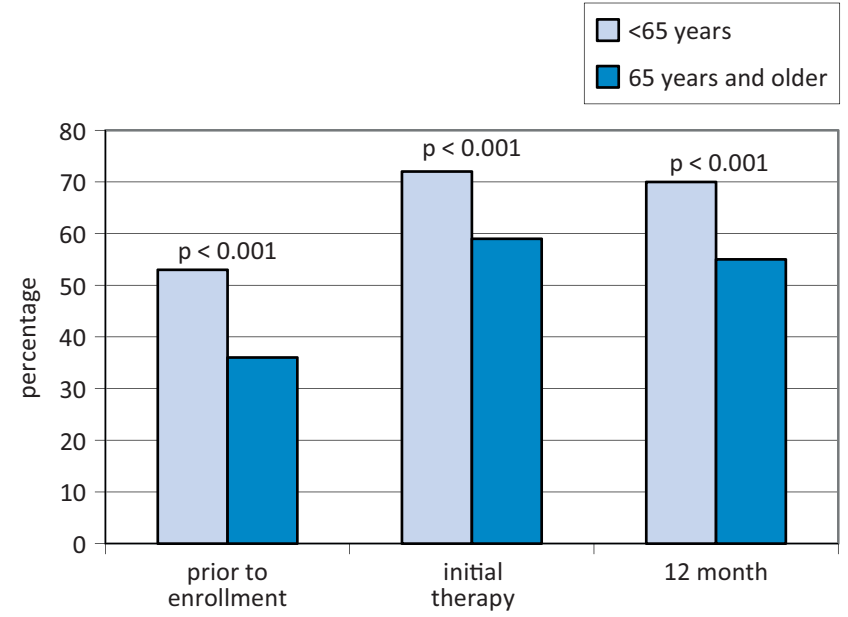

Fig. 1. The total use an aldosterone antagonist during the observation in different age groups

12 months, $93 \%$ of younger patients applied $\beta$-blockers vs $88 \%$ of the elderly. The difference again was statistically significant $(\mathrm{p}<0.005)$.

In each step of the trial, we observed statistically significant more frequent use of aldosterone-antagonists in the younger group (Fig. 1).

In the case of diuretics, the frequency of their use did not differ significantly. It amounted, prior to enrollment, to $62 \%$ for younger patients and $63 \%$ for the elderly $(\mathrm{p}=0.745)$. During initial observations, this frequency was respectively $83 \%$ vs $85 \%(\mathrm{p}=0.466)$. After 12 months, it was $74 \%$ vs $80 \%(p=0.241)$. A relatively significant percentage of patients in both groups received a second diuretic, not an aldosterone-antagonist. Among those under 65 years of age, it was $10 \%$ compared to $5 \%$ for the group of patients 65 years and over $(\mathrm{p}<0.005)$ prior to enrollment. In the initial observation, it increased to $25 \%$ vs $20 \%$ ( $p=0.093$ ).

Before inclusion, the percentage of patients treated with digoxin was $23 \%$ for younger ones and $16 \%$ for older ones ( $\mathrm{p}=0.026$ ). During the initial follow-up, it was $33 \%$ and $24 \%$, respectively. After 12 months, the proportion of patients treated with digoxin decreased to $27 \%$ in the younger patients and to $21 \%$ in the older group ( $\mathrm{p}=0.062)$.

Statins, which do not directly affect the course of HF treatment, are often used in the treatment of patients with HF. Before inclusion, the frequency of use of statins was the same, regardless of the age group $-54 \%$ for younger patients vs $53 \%$ for older ones $(\mathrm{p}=0.806)$. During the initial observation, it increased to $65 \%$ vs $69 \%$ ( $p=0.160)$, respectively. After 12 months, it remained high and amounted to $62 \%$ vs $62 \%$ ( $\mathrm{p}=0.896)$, respectively. On the other hand, the frequency of use of nitrates remained low. However, it was statistically significantly higher in the elderly $9 \%$ vs $21 \%$ ( $p<0.001)$ prior to enrollment. During the initial follow-up, it was $13 \%$ for younger vs $27 \%$ for older patients $(\mathrm{p}<0.001)$. After 12 months, in any age group, there was no longer anyone receiving nitrates. The percentage of people taking calcium channel blockers was 
Table 2. The most commonly used drugs with basic groups in the treatment of heart failure. The division depending on the group of drugs, including ACE-I, ARB, beta-blockers, and aldosterone antagonists. Changes in the frequency of use of individual drugs during therapy

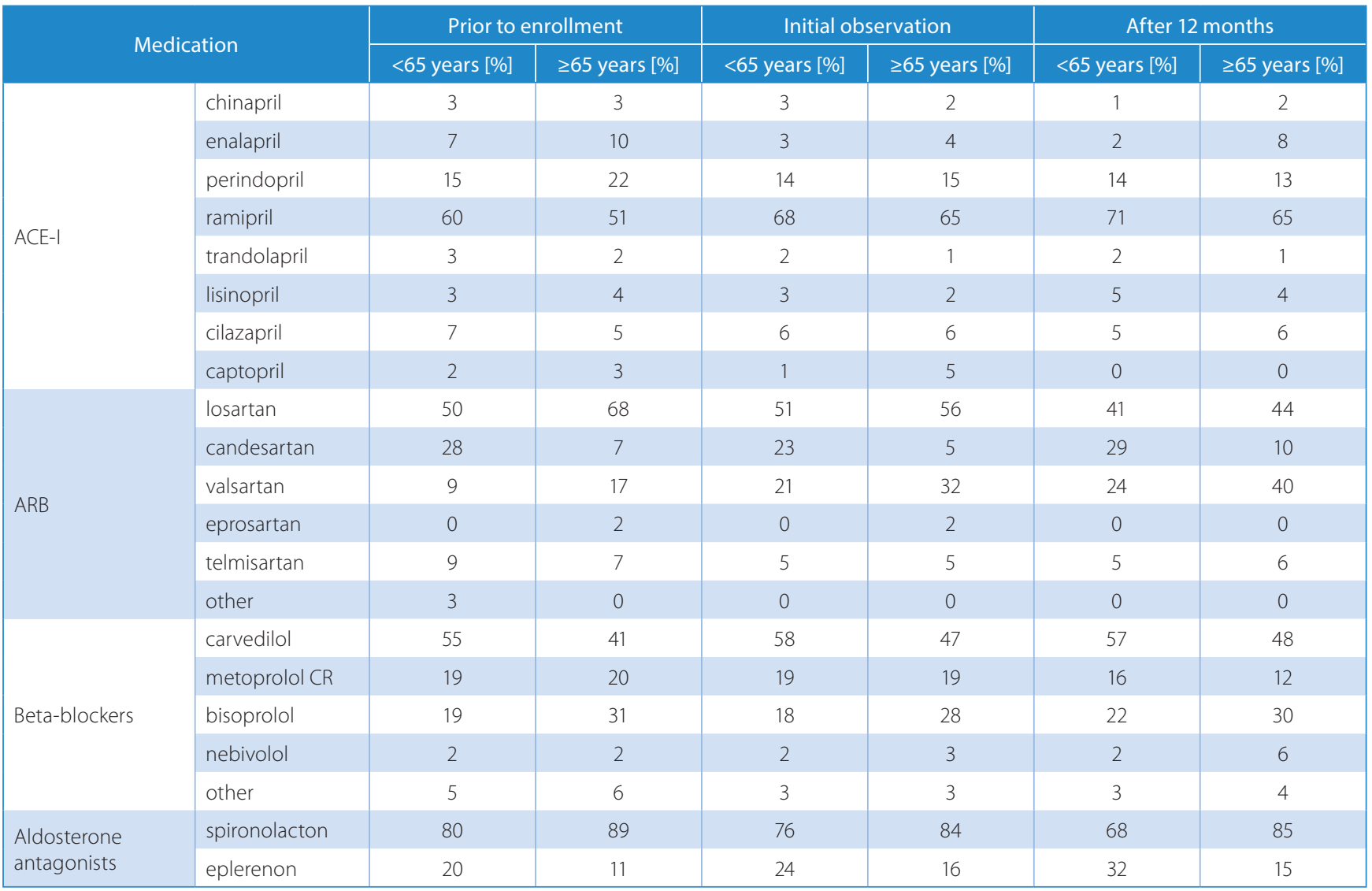

similar to the percentage of patients taking nitrates. It was higher in older people throughout the observation period. Before enrollment, 9\% of younger patients were treated, compared to $15 \%$ in the older group ( $\mathrm{p}=0.021$ ), and during the initial observation it increased up to $12 \%$ vs $18 \%(\mathrm{p}=0.011)$, respectively. Before enrollment into the study, half of the respondents took antiplatelet drugs. This percentage was $52 \%$ in the younger and $56 \%$ in the older group ( $p=0.231)$. In the initial observation, it reached $61 \%$ vs $70 \%(p=0.006)$, respectively. They are used more often by people over 65 years of age. After 12 months, it amounted to $60 \%$ vs $65 \%$ and did not differ significantly ( $p=0.197$ ). A similar percentage of people took oral anticoagulants prior to the study, i.e., $32 \%$ and $30 \%$ ( $p=0.474)$, (younger vs older). In the initial follow-up, it was up to $43 \%$ vs $50 \%(\mathrm{p}=0.530)$, and after 12 months only $32 \%$ vs $34 \%(\mathrm{p}=0.622)$. A small percentage of patients with HF received antiarrhythmic drugs, mostly amiodarone. Also, a negligible percentage of patients received antidepressants. It was in fact $5 \%$ of younger patients vs $3 \%$ of older ones of patients $(p=0.061)$ prior to enrollment. In the initial observation, the percentage of people taking antidepressants was $8 \%$ of younger patients vs $4 \%$ of older ones ( $p=0.008)$, being significantly higher in the younger group. A small percentage of patients received non-steroidal anti-inflammatory drugs. Before enrollment into the study, it amounted to $5 \%$ in the younger and $7 \%$ in the older group ( $\mathrm{p}=0.163)$. In the initial observation, it did not change significantly and amounted to $2 \%$ vs $4 \%$ ( $\mathrm{p}=0.181$ ), respectively. Taking into account the most important group of drugs involved in the HF treatment, Table 2 shows the most commonly used formulations of these groups of drugs. Table 3 presents the dose of the most commonly administered drugs that have been obtained in the register. The most commonly used ACEI was ramipril and perindopril. Among ARBs, the most common was losartan, with a large proportion of valsartan and candesartan. Among $\beta$-blockers, the most commonly used preparation in each age group was carvedilol. Spironolactone is still a more frequently used preparation compared with the newer eplerenone.

The registry does not contain ivabradine and combinations of ARB and neprilysin inhibitor because at the time of data collection these drugs were not yet recommended for treatment of HF; they appeared only in the standards of ESC (2012 and 2016 version). ${ }^{3,18}$

\section{Discussion}

The elderly require a specific approach in the treatment of HF. Despite the fact that in recent years social awareness about aging and older people in Europe has increased, in the case of treatment of HF, this is not fully reflected 
Table 3. The average doses of individual preparations [mg] depending on the age of patients and changes in doses during therapy

\begin{tabular}{|c|c|c|c|c|c|c|c|}
\hline \multirow{2}{*}{\multicolumn{2}{|c|}{ Medication }} & \multicolumn{2}{|c|}{ Prior to enrollment } & \multicolumn{2}{|c|}{ Initial observation } & \multicolumn{2}{|c|}{ After 12 months } \\
\hline & & \multirow{2}{*}{$\begin{array}{l}<65 \text { years } \\
13(n=19)\end{array}$} & \multirow{2}{*}{$\begin{array}{l}\geq 65 \text { years } \\
16(n=27)\end{array}$} & \multirow{2}{*}{$\begin{array}{l}<65 \text { years } \\
18(n=11)\end{array}$} & \multirow{2}{*}{$\begin{array}{l}\geq 65 \text { years } \\
19(n=16)\end{array}$} & \multirow{2}{*}{$\begin{array}{l}<65 \text { years } \\
22(n=5)\end{array}$} & \multirow{2}{*}{$\begin{array}{l}\geq 65 \text { years } \\
16(n=18)\end{array}$} \\
\hline \multirow{6}{*}{ ACE-I } & enalapril & & & & & & \\
\hline & perindopril & $7(n=27)$ & $6(n=54)$ & $7(n=33)$ & $6(n=46)$ & $8(n=24)$ & $7(n=27)$ \\
\hline & ramipril & $7(n=103)$ & $7(n=102)$ & $8(n=133)$ & $8(n=161)$ & $8(n=106)$ & $8(n=110)$ \\
\hline & trandolapril & $2(n=5)$ & $2(n=2)$ & $2(n=5)$ & $2(n=2)$ & $2(n=4)$ & $2(n=2)$ \\
\hline & lisinopril & $14(n=8)$ & $13(n=13)$ & $16(n=7)$ & $15(n=7)$ & $17(n=9)$ & $16(n=8)$ \\
\hline & captopril & $38(n=2)$ & $25(n=2)$ & $50(n=1)$ & $63(n=8)$ & - & - \\
\hline \multirow{4}{*}{ ARB } & losartan & $49(n=15)$ & $51(n=40)$ & $51.4(n=22)$ & $51(n=35)$ & $53(n=18)$ & $53(n=28)$ \\
\hline & candesartan & $12(n=9)$ & $10(n=4)$ & $12.6(n=10)$ & $11(n=3)$ & $10(n=12)$ & $10(n=5)$ \\
\hline & valsartan & $107(n=3)$ & $128(n=10)$ & $106.7(n=9)$ & $126(n=20)$ & $108(n=10)$ & $101(n=25)$ \\
\hline & telmisartan & $53(n=3)$ & $60(n=4)$ & $30.0(n=2)$ & $53(n=3)$ & $60(n=2)$ & $50(n=4)$ \\
\hline \multirow{4}{*}{ Beta-blockers } & carvedilol & $40(n=84)$ & $35(n=34)$ & $38(n=110)$ & $32(n=55)$ & $39(n=85)$ & $32(n=58)$ \\
\hline & metoprolol CR & $75(n=56)$ & $58(n=70)$ & $70(n=66)$ & $62(n=82)$ & $88(n=41)$ & $68(n=34)$ \\
\hline & bisoprolol & $6(n=40)$ & $6(n=61)$ & $6(n=45)$ & $6(n=68)$ & $7(n=43)$ & $7(n=51)$ \\
\hline & nebivolol & $6(n=6)$ & $5(n=3)$ & $6(n=5)$ & $5(n=7)$ & $7(n=3)$ & $5(n=11)$ \\
\hline \multirow{2}{*}{$\begin{array}{l}\text { Aldosterone } \\
\text { antagonists }\end{array}$} & spironolacton & $37(n=164)$ & $35(n=158)$ & $47(n=210)$ & $43(n=250)$ & $39(n=129)$ & $35(n=147)$ \\
\hline & eplerenon & $36(n=39)$ & $33(n=20)$ & $36(n=66)$ & $31(n=46)$ & $34(n=59)$ & $29(n=27)$ \\
\hline
\end{tabular}

Table 4. The average doses of individual preparations [mg] depending on the age and atrial fibrillation status. There were no statistically significant differences in drug doses between patients with atrial fibrillation and sinus rhythm in individual age groups

\begin{tabular}{|c|c|c|c|c|c|}
\hline \multirow{2}{*}{\multicolumn{2}{|c|}{ Medication }} & \multicolumn{2}{|l|}{$<65$ years } & \multicolumn{2}{|l|}{$\geq 65$ years } \\
\hline & & \multirow{2}{*}{$\begin{array}{l}\text { atrial fibrillation (permanent) } \\
\qquad 4.9\end{array}$} & \multirow{2}{*}{$\begin{array}{c}\text { sinus rhythm } \\
6.0\end{array}$} & \multirow{2}{*}{$\begin{array}{c}\text { atrial fibrillation (permanent) } \\
5.6\end{array}$} & \multirow{2}{*}{$\begin{array}{c}\text { sinus rhythm } \\
5.5\end{array}$} \\
\hline & perindopril & & & & \\
\hline GL & ramipril & 4.8 & 5.7 & 5.3 & 5.5 \\
\hline \multirow{3}{*}{ ARB } & losartan & 37.5 & 46.2 & 56.3 & 50.0 \\
\hline & candesartan & 16.5 & 11.0 & 8.0 & 12.0 \\
\hline & valsartan & 120.0 & - & 112 & 133.3 \\
\hline \multirow{3}{*}{ Beta-blockers } & carvedilol & 27.5 & 26.0 & 20.1 & 17.8 \\
\hline & metoprolol CR & 70.0 & 72.9 & 60.0 & 55.9 \\
\hline & bisoprolol & 4.8 & 5.3 & 4.0 & 5.0 \\
\hline
\end{tabular}

in the guidelines and recommendations on HF. In the European Society of Cardiology (ESC) recommendations in $2008,{ }^{1}$ only 1 paragraph is devoted to the treatment of HF in patients 65 years and older. Moreover, in the next update, from 2012 and 2016, it is not mentioned at all. ${ }^{3,18}$ The elderly are characterized by the frequent coexistence of various diseases. This was confirmed in our registry. Chronic kidney disease and diabetes occurred significantly more often. Also, in significantly more frequent cases, $\mathrm{AF}$ and HF were more advanced. This data is consistent with that obtained by Komajda et al. ${ }^{19}$ In this observation, patients older than 80 years were characterized by much more advanced changes and a higher incidence of comorbidities. Etiology of HF was consistent with previous observations. According to the POLCARD-HF registry conducted in Poland in 2003-2007, patients with HF and ischemic background were significantly older than those with non-ischemic cause of HF. ${ }^{20}$

\section{Treatment}

One of the basic groups of drugs with proven efficacy used in the treatment of HF are ACE-I. The percentage of people treated with these preparations was high and statistically significantly different depending on the age group. At every stage of the follow-up, the percentage of people treated with ACE-I was higher in younger patients. Considering the use of ACE-I or ARB, the percentage of people taking these drugs was even higher, reaching over $95 \%$ in the younger group and almost $90 \%$ in the elderly. During the observation, the percentage of patients treated taking ACE-I declined, with a simultaneous increase in the use of the ARB. This may indicate the appearance of adverse effects of ACE-I, which led to a switch to an alternative therapy. The most troublesome adverse effect connected with ACE-I drugs is coughing. It occurs often, in from $5-21 \%$ to almost $50 \%$ of the treated 
population. ${ }^{21-23}$ The frequency does not appear to depend on the age of the patients. ${ }^{24}$ Perhaps this is one of the main reasons for the transition to the ARB treatment. The most important side effects of both ACE-I and ARBs include renal function deterioration. The studied elderly population was characterized by the presence of more than twice as frequent chronic kidney disease. This fact can decrease the frequency of use of ACE-I/ARBs. This may be one of the reasons for the existence of a group of patients who do not use any of these drug groups.

The most commonly used ACE-I in both age groups proved to be ramipril and perindopril. However, the doses of drugs recommended in the ESC guidelines for any of the preparations used were not achieved. ${ }^{3,14,18}$ These doses were similar and did not depend significantly on the age group. This fact concerning the Polish population coincided with the results obtained in the whole registry. ${ }^{17}$ As indicated by numerous publications, despite not achieving the recommended doses, the use of smaller doses also has a positive effect on the survival of patients with HF. ${ }^{25,26}$

As in the case of the ACE-I/ARB, the frequency of used $\beta$-blockers also looks optimistic, reaching over $90 \%$ in younger and almost $90 \%$ in older patients. What is even more interesting is the fact that the frequency of $\beta$-blockers use did not decrease during the 12 month follow-up. Unfortunately, the drugs did not achieve recommended target dose. These observations are consistent with the general register. ${ }^{17}$ Of the $4 \beta$-blockers with proven efficacy in the treatment of $\mathrm{HF}$, only nebivolol is intended for the elderly population. Other $\beta$-blockers such as carvedilol, bisoprolol and metoprolol succinate do not show significant differences in the benefits derived from their use, depending on age. This is confirmed by a meta-analysis conducted by Dulin et al. ${ }^{27}$ involving more than 12,000 patients. Similar results were obtained by Sin et al. ${ }^{28}$ and Pascual-Figal et al. ${ }^{29}$ further indicating that this beneficial effect is not reduced in elderly patients with multiple comorbidities, including chronic obstructive pulmonary disease (COPD). Of course, special attention should be given to the correct initiation of treatment with $\beta$-blockers and possible side effects. Possible side effects did not translate into decreased frequency of $\beta$-blockers use after 12 months, remaining at a nearly 90\% level. Among the $\beta$-blockers, carvedilol was the most common, regardless of the age group, which draws attention to a negligible proportion of patients treated with nebivolol despite SENIORS study results. In this case, there are no conditions capable of explaining this observation.

Among the aldosterone-antagonists, spironolactone still ranks highest in comparison to eplerenone. The frequency of the application of that class of drugs was significantly lower in older patients. This difference persisted throughout the observation period. After the publication of results research RALES ${ }^{30}$ and EPHESUS ${ }^{31,32}$, it became clear that they are a very valuable component in the treatment of HF. Unfortunately, their use is limited by side effects, especially in the case of spironolactone. The most important side effect is connected to hyperkalemia, especially when combined with ACE-I/ARB. This risk considerably increases in the case of kidney damage, especially in creatinine clearance $50<\mathrm{mL} / \mathrm{min}$, which is more common in older people. ${ }^{33,34}$ These people require more frequent monitoring of serum creatinine and potassium levels. A relatively high percentage of patients were treated with diuretics - loop or thiazide, of which $20 \%$ require 2 diuretics, not including aldosterone antagonists. This did not differ according to age. An interesting, though unexplained, issue remains the high percentage of people using these drugs in the younger age group. Perhaps this is due to a different etiology of HF, e.g., hypertension, where diuretics are one of the main therapeutic groups. This was consistent with the data for the entire registry, in which the frequency of the use of diuretics was $82 \% .{ }^{17}$ In contrast, the frequency of diuretic therapy was less than that described by Komajda et al., ${ }^{19}$ where it reached above $90 \%$. Also, according to Zugck et al., ${ }^{35}$ the proportion of diuretics was 74.7-96.7\%. The use of diuretics is associated with a number of possible side effects, including electrolyte disorder, deterioration of renal function and excessive dehydration. ${ }^{24}$ Similarly, a relatively high percentage of people were treated with digoxin. Initially, it was $16 \%$ in the group of older people, and after 1 year of observation, it was even higher and amounted to $21 \%$. A similar percentage of those using digoxin was noted by CichockaRadwan et al. ${ }^{36}$ among people over 80 years of age, which was $13.7 \%$. Interestingly, in our analysis, the frequency of digoxin use was higher in the group of younger people (under 65 years of age). Perhaps the explanation of this phenomenon should be sought in a greater number of diseases coexisting in the older age group, including disorders of kidney function, liver and electrolyte disorders that contraindicate this type of treatment.

One of the major problems in the treatment of $\mathrm{HF}$ is the coexistence of arrhythmias, particularly AF. The incidence of AF increases with age. ${ }^{37-39}$ In the general population aged 65 years and older, it is $7-8 \%$, and $18 \%$ in the population over 85 years of age. The occurrence of AF significantly increases the risk of thromboembolic complications and requires additional treatment. According to the current guidelines, all individuals with HF aged 65 years or older require anticoagulation, preferably by means of oral anticoagulants. Also, most of the younger people, particularly women, also require such treatment in the absence of significant contraindications. In the present register, AF was present in almost half of the elderly, and nearly $1 / 3$ of the younger patients. Oral anticoagulants in the 12 month follow-up were accepted by nearly $1 / 3$ of younger patients and a similar percentage of elderly. As can be seen, there is a large group of older people who, despite the existence of clear indications, do not receive proper treatment. Perhaps this is due to the existence of contraindications or increased risk 
of bleeding. This problem seems to require extra attention. What is positive is the less frequent treatment with drugs which lack proven efficacy, such as nitrates or digoxin. Unfortunately, there is still much to be done to achieve full implementation of the ESC recommendations. On the other hand, all the complex risks of pharmacotherapy in the elderly, with multiple comorbidities, should be taken into account. Elderly patients are also different from the younger ones in terms of their clinical profile, long-term prognosis and predictive factors. ${ }^{40}$

\section{Conclusions}

The selected results described by the authors of the Polish part of the register of HF EURObservational Research Programme: The Heart Failure Pilot Survey (ESC-HF Pilot) do not differ from the results described for the entire registry. On this basis, we will attempt to put forth some conclusions:

1. The practice of treating HF is conducted largely in accordance with the applicable guidelines.

2. The percentage of people 65 years of age who use ACE-I/ARB, $\beta$-blockers and mineralocorticoid-antagonists remains high.

3. During the 12-month follow-up, the frequency of the use of $\beta$-blockers does not decrease, and a decrease in the number subjects treated with ACE-I is compensated by increasing percentage of the use of ARB.

4. A major problem seems to be the appropriate treatment to prevent thromboembolic complications in the case of AF coexistence. There is a large group of the elderly who do not receive proper anticoagulation.

Described attempts to draw wider conclusions are very cautious. The authors are aware of the limitations of the entire project. However, our study will contribute to improving both the efficiency and safety of the treatment of HF in the elderly in Poland.

\section{ORCID iDs}

Adam Rafał Poliwczak (1) https://orcid.org/0000-0002-5281-0318 Janusz Śmigielski (i) https://orcid.org/0000-0003-0274-1446 Agnieszka Bała (1) https://orcid.org/0000-0002-8060-524X Ewa Straburzyńska-Migaj @ https://orcid.org/0000-0002-0545-3370 Agata Tymińska (1) https://orcid.org/0000-0002-6195-1024 Pawel Balsam (1) https://orcid.org/0000-0003-0441-8976 Krzysztof Ozierański (ㄷ) https://orcid.org/0000-0002-3848-0922 Agnieszka Kapłon-Cieślicka (1) https://orcid.org/0000-0003-2020-3027 Joanna Zaprutko (1) https://orcid.org/0000-0001-9869-2428 Jarosław Drożdż @i https://orcid.org/0000-0002-0732-2104

\section{References}

1. Dickstein K, Cohen-Solal A, Filippatos G, et al; ESC Committee for Practice Guidelines (CPG). ESC Guidelines for the diagnosis and treatment of acute and chronic heart failure 2008. The Task Force for the Diagnosis and Treatment of Acute and Chronic Heart Failure 2008 of the European Society of Cardiology. Developed in collaboration with the Heart Failure Association of the ESC (HFA) and endorsed by the European Society of Intensive Care Medicine (ESICM). Eur J Heart Fail. 2008;10(10):933-989.
2. Hunt SA, Abraham WT, Chin MH, et al. 2009 focused update incorporated into the ACC/AHA 2005 Guidelines for the Diagnosis and Management of Heart Failure in the Adults: A report of the American College of Cardiology Foundation/American Heart Association Task Force on Practice Guidelines. Developed in collaboration with the International Society for Heart and Lung Transplantation. Circulation. 2009;119(14):e391-479. doi:10.1161/CIRCULATIONAHA.109.192065

3. Ponikowski P, Voors AA, Anker SD, et al; ESC Scientific Document Group. 2016 ESC Guidelines for the diagnosis and treatment of acute and chronic heart failure: The Task Force for the diagnosis and treatment of acute and chronic heart failure of the European Society of Cardiology (ESC). Developed with the special contribution of the Heart Failure Association (HFA) of the ESC. Eur Heart J. 2016:37(27):2129-2200.

4. Manzano L, Escobar C, Cleland JG, Flather M. Diagnosis of elderly patients with heart failure. Eur J Heart Fail. 2012;14(10):1097-1103.

5. van Riet $E E$, Hoes AW, Limburg $A$, Landman $M A$, van der Hoeven $H$, Rutten $\mathrm{FH}$. Prevalence of unrecognized heart failure in older persons with shortness of breath on exertion. Eur J Heart Fail. 2014;16(7): 772-777. doi:10.1002/ejhf.110

6. Díez-Villanueva P, Alfonso F. Heart failure in the elderly. J Geriatr Cardiol. 2016;13:115-117. doi:10.11909/j.issn.1671-5411.2016.02.009

7. Jha SR, Ha HS, Hickman LD, et al. Frailty in advanced heart failure: A systematic review. Heart Fail Rev. 2015;20:553-560. doi:10.1007/ s10741-015-9493-8

8. Metra M, Cotter G, El-Khorazaty J, et al. Acute heart failure in the elderly: Differences in clinical characteristics, outcomes, and prognostic factors in the VERITAS Study. J Card Fail. 2015;21:179-188. doi: 10.1016/j.cardfail.2014.12.012

9. Mahjoub H, Rusinaru D, Soulière V, Durier C, Peltier M, Tribouilloy C. Long-term survival in patients older than 80 years hospitalized for heart failure. A 5-year prospective study. Eur J Heart Fail. 2008;10(1):78-84.

10. Cherubini A, Oristrell J, Pla X, et al. The persistent exclusion of older patients from ongoing clinical trials regarding heart failure. Arch Intern Med. 2011;171(6):550-556. doi:10.1001/archinternmed.2011.31

11. Flather MD, Shibata MC, Coats AJ, et al; SENIORS Investigators. Randomized trial to determine the effect of nebivolol on mortality and cardiovascular hospital admission in elderly patients with heart failure. Eur Heart J. 2005;26(3):215-225.

12. Gustafsson F, Torp-Pedersen C, Seibaek M, Burchardt H, Kober L; DIAMOND study group. Effect of age on short and long-term mortality in patients admitted to hospital with congestive heart failure. Eur Heart J. 2004;25(19):1711-1717.

13. Cohen-Solal A, Desnos M, Delahaye F, Emeriau JP, Hanania G. A national survey of heart failure in French hospitals. The Myocardiopathy and Heart Failure Working Group of the French Society of Cardiology, the National College of General Hospital Cardiologists and the French Geriatrics Society. Eur Heart J. 2000;21(9):763-769.

14. Rywik TM, Kołodziej P, Targoński R, et al. Characteristics of the heart failure population in Poland: ZOPAN, a multicentre national programme. Kardiol Pol. 2011;69(1):24-31.

15. Sztramko R, Chau V, Wong R. Adverse drug events and associated factors in heart failure therapy among the very elderly. Can Geriatr $J$. 2011;14(4):79-92.

16. Zaprutko J, Michalak M, Nowicka A, et al. Hospitalization length and prognosis in heart failure patients. Kardiol Pol. 2017;75(4):519-526. doi:10.5603/KP.a2017.0088

17. Maggioni AP, Dahlström U, Filippatos $G$, et al; Heart Failure Association of ESC (HFA). EURObservational Research Programme: The Heart Failure Pilot Survey (ESC-HF Pilot). Eur Heart J. 2010;31:1023-1031.

18. McMurray JJ, Adamopoulos S, Anker SD, et al; ESC Committee for Practice Guidelines. ESC Guidelines for the diagnosis and treatment of acute and chronic heart failure 2012: The Task Force for the Diagnosis and Treatment of Acute and Chronic Heart Failure 2012 of the European Society of Cardiology. Developed in collaboration with the Heart Failure Association (HFA) of the ESC. Eur Heart J. 2012; 33(14):1787-1847.

19. Komajda M, Hanon O, Hochadel M, et al. Contemporary management of octogenarians hospitalized for heart failure in Europe: Euro Heart Failure Survey II. Eur Heart J. 2009;30(4):478-486.

20. Zieliński T, Kurjata P, Korewicki J; participants of POLKARD-HF. Prognosis in patients with severe heart failure referred for heart transplantation-POLKARD-HF 2003-2007. Int J Cardiol. 2010;145(2):242-244. 
21. Gokhale M, Girman C, Chen Y, Pate V, Funk MJ, Stürmer T. Comparison of diagnostic evaluations for cough among initiators of angiotensin converting enzyme inhibitors and angiotensin receptor blockers. Pharmacoepidemiol Drug Saf. 2016;25(5):512-520. doi:10.1002/ pds.3977

22. Hallberg P, Nagy J, Karawajczyk M, et al. Comparison of clinical factors between patients with angiotensin-converting enzyme inhibitor-induced angioedema and cough. Ann Pharmacother. 2017;51(4): 293-300. doi:10.1177/1060028016682251

23. Woo KS, Nicholls MG. High prevalence of persistent cough with angiotensin converting enzyme inhibitors in Chinese. Br J Clin Pharmacol. 1995;40(2):141-144.

24. Rich MW. Pharmacotherapy of heart failure in the elderly: Adverse events. Heart Fail Rev. 2012;17(4-5):589-595

25. Packer M, Poole-Wilson PA, Armstrong PW, et al. Comparative effects of low and high doses of the angiotensin-converting enzyme inhibitor, lisinopril, on morbidity and mortality in chronic heart failure. ATLAS Study Group. Circulation. 1999;100(23):2312-2318.

26. Demers C, Mody A, Teo KK, McKelvie RS. ACE inhibitors in heart failure: What more do we need to know? Am J Cardiovasc Drugs. 2005; 5(6):351-359.

27. Dulin BR, Haas SJ, Abraham WT, Krum H. Do elderly systolic heart failure patients benefit from beta blockers to the same extent as the non-elderly? Meta-analysis of 12,000 patients in large-scale clinical trials. Am J Cardiol. 2005;95(7):896-898.

28. Sin DD, McAlister FA. The effects of beta-blockers on morbidity and mortality in a population-based cohort of 11,942 elderly patients with heart failure. Am J Med. 2002;113(8):650-656.

29. Pascual-Figal DA, Redondo B, Caro C, et al. Comparison of late mortality in hospitalized patients $>70$ years of age with systolic heart failure receiving beta blockers versus those not receiving beta blockers. Am J Cardiol. 2008;102(12):1711-1717. doi:10.1016/j.amjcard.2008.07.059

30. Pitt B, Zannad F, Remme WJ, et al. The effect of spironolactone on morbidity and mortality in patients with severe heart failure. Randomized Aldactone Evaluation Study Investigators. N Engl J Med. 1999;341(10):709-717.
31. Pitt B, Remme W, Zannad F, et al; Eplerenone Post-Acute Myocardial Infarction Heart Failure Efficacy and Survival Study Investigators. Eplerenone, a selective aldosterone blocker, in patients with left ventricular dysfunction after myocardial infarction. N Engl J Med. 2003; 348(14):1309-1321.

32. Krum H, Shi H, Pitt B, et al; EMPHASIS-HF Study Group. Clinical benefit of eplerenone in patients with mild symptoms of systolic heart failure already receiving optimal best practice background drug therapy: Analysis of the EMPHASIS-HF study. Circ Heart Fail. 2013;6(4): 711-718. doi:10.1161/CIRCHEARTFAILURE.112.000173

33. Juurlink DN, Mamdani MM, Lee DS, et al. Rates of hyperkalemia after publication of the randomized aldactone evaluation study. $N$ Engl J Med. 2004;351(6):543-551.

34. Eschalier R, McMurray JJ, Swedberg K, et al; EMPHASIS-HF Investigators. Safety and efficacy of eplerenone in patients at high risk for hyperkalemia and/or worsening renal function: Analyses of the EMPHASIS-HF study subgroups (Eplerenone in Mild Patients Hospitalization And Survlval Study in Heart Failure). J Am Coll Cardiol. 2013; 62(17):1585-1593. doi:10.1016/j.jacc.2013.04.086

35. Zugck C, Franke J, Gelbrich G, et al. Implementation of pharmacotherapy guidelines in heart failure: Experience from the German Competence Network Heart Failure. Clin Res Cardiol. 2012;101(4):263-272.

36. Cichocka-Radwan A, Lelonek M. Annual prognostic factors in chronic heart failure in patients over 80 years old. Kardiol Pol. 2017;75(2): 164-173.

37. Chugh SS, Havmoeller R, Narayanan K, et al. Worldwide epidemiology of atrial fibrillation: A Global Burden of Disease 2010 Study. Circulation. 2014;129(8):837-847.

38. Fitzmaurice DA, Hobbs FD, Jowett $S$, et al. Screening versus routine practice in detection of atrial fibrillation in patients aged 65 or over: Cluster randomized controlled trial. BMJ. 2007;335(7616):383.

39. Schnabel RB, Yin X, Gona P, et al. 50-year trends in atrial fibrillation prevalence, incidence, risk factors, and mortality in the Framingham Heart Study: A cohort study. Lancet. 2015;386(9989):154-162.

40. Ozierański K, Balsam P, Tymińska A, et al. Heart failure in elderly patients: Differences in clinical characteristics and predictors of 1-year outcome in the Polish ESC-HF Long-Term Registry. Pol Arch Med Wewn. 2016;126(7-8):502-513. 